\title{
Los “Poemas underwood” de Martín Adán
}

\author{
Víctor Vich \\ Pontificia Universidad Católica del Perú
}

\section{RESUMEN}

Este ensayo estudia los “Poemas underwood” que Martín Adán incluyó en "La casa de Cartón" (1928). Por sus características formales, se trata de uno de los textos más importantes de la vanguardia peruana y se trata, además, de una de las primeras y más contundentes críticas al discurso de la modernidad inaugurado en ese entonces. Me ha interesado analizar muchas de las principales imágenes de este poema a fin de rastrear no solo cuáles son los principales cambios sociales que ahí se representan, sino cómo la voz poética va configurando un contundente arsenal de respuestas críticas a ellos.

Palabras clave: Poesía peruana, Martín Adán, La casa de cartón, Poemas underwood

\section{ABSTRACT}

In this essay I study the "Underwood Poems" that Martin Adan included in "La Casa de Carton" (1928). Its formal characteristics make these poems one of the most important texts of the Peruvian vanguard, as well as they establish one of the most resounding criticism to the modernity discourse of the era. I am particularly interested in analyzing one of the main images of this poem in order to trace not only the principal social changes that are represented but also how the poetic voice configures a compelling armor of critical responses to these changes. Keywords: Peruvian poetry, Martín Adán, La casa de cartón, Underwood poems 
¿Cómo he venido a parar en este cinema perdido y humoso? Martín Adán ([1928] 1989)

La experiencia de la modernidad comenzó a ser impactante en la Lima de las primeras décadas del siglo XX. Para muchos historiadores, el proyecto moderno comenzó a activarse a partir de 1895 y emergió bajo una herencia colonial que, en el Perú, siempre se ha resistido a morir y de una cultura aristocrática que, en ese entonces, tenía monopolizadas distintas dimensiones del poder en el país (Burga y Flores Galindo 1987; Muñoz 2001).

En Europa, la modernidad se erigió como el proyecto de la razón (contra el conocimiento tradicional), de la ciencia (contra las creencias religiosas) y del culto a la tecnología y a los negocios (contra la producción precapitalista). En el Perú, se propuso reducir el poder de la aristocracia, construir un Estado más institucional e insertar al país en la economía mundial. La modernidad fue siempre un culto hacia lo nuevo, una necesidad de producir profundos cambios en la sociedad.

Me interesa comentar los famosos "Poemas underwood" que Martín Adán incluyó en La casa de cartón, como un texto de suma importancia no solo para observar muchos de los cambios sociales en curso sino, sobre todo, para subrayar las primeras respuestas críticas a la modernidad. En efecto, en este poema, el poeta no duda en representar la modernidad como un proceso cargado de experiencias disímiles. Por un lado, el poema celebra la liberación que ella trae consigo en distintos campos de la experiencia humana pero, por otro, también la describe con mucha desconfianza porque intuye su lado más oscuro y problemático. Este es un poema que se propuso mostrar algunas de las contradicciones centrales de este proceso y no quiso abstenerse de producir una contundente crítica al respecto.

De hecho, Martín Adán fue un observador privilegiado de tal proceso. Su familia era una síntesis muy tensa de nuevas y viejas identidades políticas. Sobre su padre, se sabe que venía de una importante familia del puerto de Pacasmayo al norte del Perú, aunque se dedicó a la vida bohemia y murió muy joven. De lado de 
su madre, se trataba de una familia de costumbres aristocráticas, que poco a poco se fueron reconvirtiendo en una burguesía ilustrada. Su abuelo fue un destacado ginecólogo que acumuló una considerable fortuna y, gracias a ella, la madre y la tía Tarcila pudieron comprar una casa, un coche y vivir cómodamente, al menos algunos años. Martín Adán creció en un ambiente muy tradicional, pero asistió a una escuela cosmopolita que lo abrió hacia nuevas ideas y sensibilidades (Vargas Durand: 1995). Es en ese sentido que Lauer ha sostenido que se trató de un personaje que encarnó muchas de las crisis que emergieron para hacer nacer el siglo XX peruano. El poeta las sufrió todas, no supo bien qué hacer con ellas, pero lo que sí hizo fue apostar por la escritura poética como una forma de exorcismo político y de búsqueda personal (1983: 19). El caso de Martín Adán es, sin duda, uno de los más significativos del proceso poético en el Perú contemporáneo.

Ingresemos ya al poema aludido. Comencemos subrayando que la modernidad prometía que el progreso y la felicidad estaban en relación directa con los avances tecnológicos y con la acumulación de capital. La vida cotidiana había comenzado a transformarse a efectos de un conjunto de objetos que supuestamente la harían mucho más fácil. La modernidad prometía un mundo renovado y veloz, cargado de oportunidades y, así, el automóvil (que llegó a Lima en 1902) se convirtió pronto en el actor principal de un contexto urbano que veía la felicidad a la vuelta de la esquina. Este poema se encargará de registrar todo ese optimismo, pero, al mismo tiempo, comenzará a producir un hiato entre el discurso oficial sobre ese nuevo mundo moderno y la experiencia subjetiva: se trata de la emergencia de una posición crítica que no puede dejar de desconfiar de dichas promesas. Detengámonos en estos versos:

Ahora puedo embarcarme en un transatlántico. E ir pescando Durante la travesía aventuras como peces.

Pero ¿a dónde iría yo?

El mundo me es insuficiente.

(Adán [1928] 1989: 61) 
Utilizando la imagen de esos grandes buques que comenzaban a surcar los océanos a mayor velocidad, los versos muestran aquel discurso que sostenía que la modernidad era capaz de ofrecer una renovación extrema de la experiencia humana en vías a un mayor control sobre el mundo. Sin embargo, esta es una voz que aspira a mantener un cierto nivel de autonomía frente al aluvión de los cambios sociales. Notemos, en efecto, que lo que aquí emerge es una subjetividad que ha comenzado a desorientarse y que no está dispuesta a renunciar a su vocación crítica. A lo largo del poema, podemos observar que la voz va sintiéndose mareada entre tantos objetos y que nunca queda subsumida en dichas ilusiones. Digamos entonces que este es un sujeto que no se deja seducir porque ha comenzado a descubrir que hay algo falso en el discurso moderno. Por eso mismo, una opción profundamente irónica comienza a emerger en el poema.

Los automóviles te soban las caderas, volviendo la cabeza. Cree tú que son mujeres viciosas. Así tendrás tu aventura y tu sonrisa para después de la cena.

(Adán [1928] 1989: 59)

Estos versos hacen visible la trampa y revelan el surgimiento de una sociedad que ha comenzado a transformar la realidad en puras imágenes libidinales. Como lo ha explicado Žižek (1992), no es que los sujetos modernos creamos directamente en las propiedades mágicas de los objetos, sino que todos actuamos como si creyéramos. La modernidad produce signos que prometen darle al cuerpo y al espíritu una forma mágica (Bauman 2007: 147). El poeta se da cuenta de que el fetiche no es una ilusión subjetiva, sino que, en el mundo moderno, se encuentra encarnado en las prácticas materiales. Dicho de otra manera: el poema se aboca a representar el imperativo de goce, ese mandato al consumo que caracteriza a la sociedad contemporánea descrita hoy como "sociedad del espectáculo" (Debord 2010). 
El poeta nota, además, que este nuevo escenario de promesas y felicidad es paralelo a otro de un mayor control social, vale decir, a una mayor presencia del Estado en la vida cotidiana y, por tanto, a una pérdida de libertad individual. En estos versos, el Estado aparece representado como una instancia de vigilancia, como una institución anclada en una gravísima contradicción pues si, por un lado, permite el exceso del mercado, por otro, se dedica a reprimir otro tipo de excesos.

En ese sentido, el poema es muy hábil en representar cómo los procesos de constitución de la subjetividad se encuentran directamente ligados a procesos de sujeción o dominación social. En el mundo moderno, un ciudadano solo se vuelve sujeto "si queda sujetado a lo que simultáneamente lo vuelve objeto", tal como ha sostenido Roberto Esposito (2012: 281). Es decir, un sujeto solo emerge como tal a efecto de sentirse llamado (léase "controlado", "sujetado") por algún tipo de poder que ha establecido previamente las coordenadas de su movimiento. "Tu corazón es una bocina prohibida por las ordenanzas de tráfico", ${ }^{1}$ dice el verso con la intención de subrayar las duras transformaciones que la modernidad ha comenzado a activar en la subjetividad. En este poema, el Estado es una instancia que desacredita cualquier opción que se sitúe fuera del pragmatismo utilitarista. "Si dejaras saber que eres un poeta, irías a la comisaría”, subraya el poema para marcar la imposición de una nueva racionalidad dominante.

Notemos la paradoja o entrampamiento que la voz poética descubre sobre la constitución del mundo moderno: el mercado no puede ofrecer la felicidad, pero la ofrece; el Estado tampoco puede proveerla, pero actúa como si pudiera hacerlo. Los versos lo dicen poéticamente: "el mundo no está precisamente loco, pero sí demasiado decente". Bajo esa situación, hay que notar que nos encontramos ante una voz que se ha descubierto situada en el medio

\footnotetext{
En adelante, los versos de los "Poemas underwood" (Adán [1928] 1989) citados dentro del cuerpo del texto aparecerán manteniendo el formato dado por el autor. Solo cuando sean citas separadas del texto tendrán la referencia parentética completa.
} 
de una trampa. A pesar de representar un escenario performativamente prometedor, ha descubierto que su margen de libertad es mínimo. En realidad, el poema revela que es falso que el sujeto moderno tenga libertad y pueda moverse mucho. Más bien, descubre, con algo de pánico, que ha quedado inscrito en las trampas del mercado y que un poder panóptico ha comenzado a surgir.

Desde ahí, el poema activa también un conjunto de críticas a la democracia o, mejor dicho, al discurso idealizado que la modernidad ha producido sobre la democracia y su origen heleno. "La polis griega sospecho que fue un lupanar al que había que ir con revolver", dicen los versos sin ningún tipo de censura. De hecho, el poeta observa que la ciudad - ese nuevo mundo saturado de ilusiones - se ha llenado de antagonismos sociales que, por un lado, dan cuenta de nuevas formas de explotación y desigualdad social ("Pasaban los obreros con los ojos resentidos con la tarde, con la ciudad y con los hombres") y, por otro, del surgimiento de un mundo burocrático, rutinario y ciertamente desencantado: "los hombres que tropiezas tienen la carne encallecida de oficina", se dice astutamente.

Insistamos: este es un poema donde la voz poética pierde el miedo para radicalizar críticas al discurso moderno y se ha dedicado a construir imágenes que comienzan a desacreditarlo y a mostrar su verdad oculta. Es cierto que el mundo se ha desencantado porque lo nuevo es pragmático y racionalista ("los yanquis tienen la carne demasiado fresca, casi fría, casi muerta”, dice un verso), pero es aún más verdadero que lo ha vuelto a reencantar con nuevas ofertas y promesas utilitaristas. Este es un poema que insiste en su iniciativa desacralizante, en su espíritu crítico, en su opción iconoclasta, pero precisemos que aquí nunca ocurre la adscripción a una ideología política concreta. Es cierto que por aquellos años Martín Adán fue muy amigo de Mariátegui ("Un hombre de gran temple moral, un héroe trágico", así lo definió en una oportunidad), pero es también verdadero que, desde muy joven, se desinteresó por la política y que imágenes de este tipo nunca más volvieron a aparecer en su poesía. 
El mundo está demasiado feo y no hay manera de embellecerlo. Solo puedo imaginarlo como una ciudad de burdeles y fábricas bajo un aletazo de banderas rojas.

(Adán [1928] 1989: 61)

¿Qué función cumplen estas banderas rojas en el marco del poema? ¿Sirven para mostrar algún tipo de opción política? ¿Sirven para señalar el camino hacia la emancipación frente al capitalismo existente? Quizá haya existido algo de aquello en ese momento (solo en ese momento), pero se trata, sobre todo, de criticar la arrogancia con la que la modernidad se presentaba al momento. Este es un poema que ha encontrado una verdad y que se está esforzando por comunicarla ¿Cuál es ella? La que afirma que los antagonismos sociales no se pueden ocultar y que el mundo moderno sigue siendo, salvajemente, un mundo en disputa.

Preguntémonos ahora cuáles son las consecuencias de estas tensiones en el ámbito individual. De hecho, la modernidad también se propuso activar un conjunto de transformaciones en los procesos de subjetivación personal que son los que refieren a una nueva manera de experimentarse en el mundo. Sometidos a un nuevo conjunto de mandatos, los sujetos comenzaron a definirse de otra manera y nuevos modelos de identidad aparecieron en la escena.

Nací en una ciudad, y no sé ver el campo.

Me he ahorrado el pecado de desear que fuera mío.

En cambio deseo el cielo.

Casi soy un hombre virtuoso, casi un místico.

Me gustan los colores del cielo porque es seguro que no son tintes alemanes.

Me gusta andar por las calles algo perro, algo máquina, casi nada hombre.

(Adán [1928] 1989: 60)

Los versos son tensos porque si bien comienzan señalando una condición urbana y cosmopolita, al mismo tiempo, se desmarcan de 
todo el discurso positivista que en ese entonces luchaba por imponerse. Como ya lo hemos notado, esta es una subjetividad que ya se presenta con otra sensibilidad y con otros intereses. Se trata de un sujeto que ha descubierto la artificialidad del mundo moderno (los tintes alemanes), que quiere salirse de la humanidad común ("algo perro, algo máquina, casi nada hombre”) y que no le rehúye a la opción mística. Este es un poema cuya voz siempre quiere representarse como una instancia más autónoma de lo social, aunque en permanente búsqueda de sí mismo.

Yo me siento las manos delicadas.

¿Qué soy, qué quiero? Soy un hombre y no quiero nada.

$\mathrm{O}$, tal vez, ser un hombre como los toros o como los otros.

Tú no tienes las orejas demasiadas grandes.

Yo quiero ser feliz de una manera pequeña.

Con dulzura, con esperanza, con insatisfacción, con limitación, con tiempo, con perfección.

(Adán [1928] 1989: 61)

Digamos entonces que, frente a la nueva "razón instrumental”, el poema nos enfrenta ante un sujeto que no tiene reparo en mostrar sus manos delicadas y no desacredita el trabajo artesanal que, en última instancia, refiere a la propia poesía. Frente al ansioso deseo de monumentalidad moderna, el poema nos coloca ante un sujeto que está intentando construirse bajo otros paradigmas: "yo quiero ser feliz de una manera pequeña”, dicen los versos y, así, esta voz se desmarca de ese ilimitado deseo de acumulación capitalista y de control sobre el mundo. "No quiero ser feliz con permiso de la policía”, también se sostiene con pavor.

A contraposición del discurso moderno que se había dedicado a crear la ilusión de un mundo lleno de libertad y felicidad, Martín Adán observó, más bien, la emergencia de un mundo con pocos recursos y cargado de restricciones. Si la modernidad fue la fe en el individuo racional y la apología del capitalismo, este poema parecería representar, por el contrario, a un sujeto que no está seguro de 
poder manejar su propio destino porque se ha descubierto sometido a una nueva presión y a nuevas formas de poder. "Estoy sin pasado y con un futuro excesivo", dice para señalar, con agonía, una identidad que se ha descentrado - que no entiende bien lo que sucede-, pero que insiste en defender algo de su propia singularidad. "No estoy muy convencido de mi humanidad; no quiero ser como los otros", dice enfáticamente.

El mundo no está precisamente loco, pero sí demasiado decente.

No hay manera del hacerle hablar cuando está borracho.

Cuando no lo está, abomina la borrachera o ama a su prójimo.

Pero yo no sé sinceramente qué es el mundo ni qué son los hombres

Solo sé que debo ser justo y honrado y amar a mi prójimo, Y amo a los mil hombres que hay en mí, que nacen y mueren a cada instante

Y no viven nada

He aquí mis prójimos.

La justicia es unas estatuas feas en las plazas de las ciudades. Ninguna de ellas me gusta ni poco ni mucho - no son diosas ni mujeres.

Yo amo la justicia de las mujeres sin túnica y sin divinidad.

(Adán [1928] 1989: 59-60)

La sociedad se ha vuelto performativa e hipócrita y, por eso, se emborracha de tecnología, pero censura otro tipo de borracheras. Hemos dicho que esta es una voz desorientada, pero lo cierto es que todavía tiene la capacidad de poder emitir una sentencia. Frente a la acumulación de frivolidad, el sujeto conserva buena parte de su conciencia moral y afirma la necesidad de ser justo, honrado y amar al prójimo. Este juicio, sin embargo, deja de ser al instante totalizante o trascendental. Muy rápido, los versos desestabilizan toda solemnidad y todo carácter pedagógico. No se trata entonces 
de un principio a priori que no pueda deconstruirse porque, en este poema, todo puede ser festiva y agónicamente deconstruido. La modernidad — sostiene Groys - es un periodo en el que el presente se experimenta dolorosamente como una transición de la tradición familiar hacia el futuro desconocido (2016: 156).

Digamos, en suma, que a pesar de su vanguardismo estético, este es un poema que desconfía de todo discurso suturado y que, más bien, ha optado por mostrar un conjunto de contradicciones y vacíos. En realidad, si algo exaspera a esta voz poética es la posición arrogante y autosuficiente con que la modernidad se presentaba a sí misma. Los versos sostienen que ella no agota la experiencia humana y que no explica ni resuelve el misterio o la complejidad de la vida. Por eso, frente a un escenario seductor, pero fundamentalmente falso, este es un poema que ha optado por una condición lírica que no está dispuesta a perder su carácter meditativo ni su opción crítica.

$* * *$

$¿$ ¿s este un poema políticamente conservador? ¿Son estos versos los portadores de una posición reaccionaria frente al "progreso" social? Parecería que sí, pero en realidad pienso que no se trata de ello. Los "Poemas underwood" son, sobre todo, un texto crítico que muestra una ardiente pugna por definir otro sentido de la vida. Este es un texto que se propuso visibilizar las limitaciones de todo lo que en ese entonces comenzaba a imponerse, de manera autoritaria, como el ideal a seguir. Este es un poema que coge algo de la modernidad (la estética de vanguardia, por ejemplo), pero que no está dispuesto a subsumirse en un chantaje totalizador.

Ahora bien, si el autor reacciona duramente contra la modernidad, no lo hace porque piense que en el pasado -o en la tradición- se encuentren mejores respuestas. De hecho, toda La casa de cartón es un alegato contra un pasado también agobiante y sumamente opresivo. Más allá del descentramiento del sujeto, 
de la ironía del narrador y del quiebre del lenguaje mimético, un verdadero desacuerdo con el mundo, "una ética disidente" es fundamentalmente lo que caracteriza a este libro (Elmore 1993: 66). Desde ahí, el poema muestra una nueva posición subjetiva que optó por comenzar a deconstruirse desde un compromiso ciertamente anticapitalista pero, sobre todo, desde su involucramiento fiel con las dimensiones más oscuras de la experiencia humana. Para Lauer, "se precisaba un conservador de fondo, como Adán, para establecer con ironía y acoso, de extrañeza y deslumbramiento, de distancia y familiaridad entre lo moderno y lo tradicional en el Perú" (1983: 16).

Podemos decir entonces que, en este poema ( $y$ en el resto de su obra), Martín Adán se salió del encasillado debate tradición/ modernidad, pues se dio cuenta de que ninguna de las dos opciones zanjaba o suturaba los problemas centrales de la vida. El malestar estructural de la condición humana, el deseo de absoluto y la agonía de sentirse siempre en falta no son problemáticas que puedan resolverse a partir de dicha dicotomía. Desde muy temprano, Martín Adán descubrió que "el mundo es demasiado grande e insuficiente" y que la vida humana está inscrita en un complejo drama que nunca podrá resolverse del todo. "[L]a felicidad no basta para ser feliz", sostuvieron estos versos estremecidos. Para los "Poemas underwood", la modernidad miente y la tradición miente también: el poema descubre que es imposible controlar el mundo como a uno le da la gana.

\section{Referencias bibliográficas}

ADáN, Martín

[1928]1989 La casa de cartón. Lima: Peisa.

Burga, Manuel y Alberto Flores Galindo

1987 Apogeo y crisis de la república aristocrática. Lima: Rikchay.

Debord, Guy

[1928] 2010 La sociedad del espectáculo. Valencia: Pre-textos. 
Elmore, Peter

1993 Los muros invisibles. Lima y la modernidad en la novela del siglo XX. Lima: Mosca azul editores/Caballo Rojo.

Esposito, Roberto

2012 Diez pensamientos acerca de la política. Buenos Aires: Fondo de Cultura Económica.

Groys, Boris

2016 Arte en flujo. Ensayos sobre la evanescencia del presente. Buenos Aires: Caja negra.

LaUer, Mirko

1983 Los exilios interiores. Una introducción a Martín Adán. Lima: Hueso húmero ediciones.

MuÑoz, Fanni

2001 Diversiones públicas en Lima. 1890-1920. La experiencia de la modernidad. Lima: Red para el desarrollo de las ciencias sociales en el Perú.

Vargas Durand, Luis

1995 Martín Adán. Lima: Brasa.

ŽIZEK, Slavoj

1992 El sublime objeto de la ideología. México D.F.: Siglo XXI. 